\title{
The ISPS 2017 editorial for the 26th annual conference on information storage and processing systems, San Francisco, California, USA
}

\author{
Paul C.-P. Chao ${ }^{1}$ Yu-Te Liao ${ }^{1} \cdot$ Yu-Jen Wang ${ }^{2}$ \\ Published online: 30 August 2018 \\ (C) Springer-Verlag GmbH Germany, part of Springer Nature 2018
}

It was our pleasure to host the special issue for the 26th ASME annual conference on information and storage and processing systems (ISPS 2017) held at Hilton San Francisco District, San Francisco, California, USA from August 29-30, 2017.

The conference offers an ideal forum for researchers in both academic and industrial societies to foster synergies in multidisciplinary areas of data storage and processing. Papers presented in this conference address advanced technologies and knowledges related to:

- Tribology, head/media interface.

- Actuator/suspension and sensor.

- Servo control technology.

- Shock and flow induced vibrations.

- Spindle motor and acoustics.

- Micro/nano technology.

- Mechatronics, robotics, and automation.

- Imaging/printing technologies and consumer electronics.

- Optical storage and future technologies.

- Flexible media mechanics and tape storage.

- Storage system and future technologies.

The ISPE 2017 was a very successful, international conference having high quality contributions from countries around the world. Many papers presented in the conference are research and development results of

Paul C.-P. Chao

pchao@mail.nctu.edu.tw

Yu-Te Liao

yudoliao@nctu.edu.tw

Yu-Jen Wang

yjwang@mail.nsysu.edu.tw

1 Department of Electrical and Computer Engineering, National Chiao Tung University, Hsinchu, Taiwan

2 Department of Mechanical and Electromechanical Engineering, National Sun Yat-sen University, Kaohsiung, Taiwan industry-university research collaborations. This conference recognizes technical contributions from researchers and students. To encourage student participation in the conference as well as to promote student research in information storage and processing systems, the ISPS 2017 provided three ISPS Division graduate student fellowships and six ISPS Division graduate student conference scholarships to waive graduate students' conference registration fees.

Authors of recommended presentations in the ISPS 2017 were invited and encouraged to submit full papers with extended technical contribution to this special issue. All submitted papers went through a rigorous peer-review process. Many reviewers are in fact world leading experts in relevant fields. Many papers went through substantially revisions before acceptance from reviewers for final publication. We sincerely thank reviewers who review the manuscripts in a thorough and constructive manner. Without the fast responses from all reviewers, this special issue will not be in production on time.

We would also like to acknowledge the help from conference staff, all session organizers, session (co-) chairs and the ISPS executive members. And special thanks to the ASME ISPS Division Chair of 2017, Prof. Kyoung-Su Park, for his great leadership to carry us through the 2017 conference. Last, but not least, a final word of gratitude goes to all presenters and participants of the conference. The ISPS 2017 would not be successful without your dedicated participation. 